\title{
DEVELOPMENT OF A HOLISTIC WELLNESS MODEL FOR MANAGERS IN TERTIARY INSTITUTIONS
}

Authors:

Petrus A. Botha

Hein Brand ${ }^{2}$

\section{Affiliations:}

${ }^{1}$ Department of Public Management, Tshwane University of Technology,

Polokwane Campus

${ }^{2}$ Department of Human Resources Management, University of Pretoria, South Africa

\section{Correspondence to:}

Petrus A. Botha

e-mail:

bothapa@tut.ac.za

Postal address:

Magasyn 94, Polokwane,

Limpopo, 0700,

South Africa

\section{Keywords:}

wellness dimensions health; wellness behaviour lifestyle; health risks

\section{Dates:}

Received: 26 Mar. 2009 Accepted: 08 July 2009

Published: 25 Sept. 2009

How to cite this article: Botha, P.A., \& Brand, H. (2009). Development of a holistic wellness model for managers in tertiary institutions. $S A$ Journal of Human Resource Management/Tydskrif vir Menslikehulpbronbestuur 7(1), Art. \#208, 10 pages. DOI: 10.4102/sajhrm.v7i1.208

\section{This article is available} at:

http://www.sajhrm.co.za

(C) 2009. The Authors. Licensee: OpenJournals Publishing. This work is licensed under the Creative Commons Attribution License.

\begin{abstract}
Individuals struggle to attain optimal wellness and health levels due to unhealthy lifestyle behaviour. A holistic wellness model was developed in this study to provide a framework for a cross-sectional survey to assess the wellness behaviour and health risk levels of managers in two South African universities. A census was done on the total population of 324 and responses were received from 89 managers. The study employed descriptive and inferential statistical procedures to analyse the quantitative data. The findings suggested that the managers had high levels of wellness behaviour and low levels of health risks. Physical fitness and nutrition as well as medical self-care wellness behaviour levels were identified as weaknesses among managers, for which urgent interventions are required.
\end{abstract}

\section{INTRODUCTION}

In November 2002, Cabinet approved proposals for the restructuring of South African higher education institutions through mergers and incorporations. This reduced the number of higher education institutions from 36 to 21. Any major change has an impact on employee wellbeing, since it is associated with increased uncertainty, resulting in increased perceptions of occupational stress, lower job satisfaction, high levels of absenteeism, a lack of trust and high mental and physical illhealth symptoms (Chunda \& Cooper, 2002; Gibson, Ivancevich \& Donnelly, 2000). The survival and longevity of the new higher education institutions will depend largely on the wellbeing of managers. Since managers, as change agents, need to provide strategic direction and leadership to the new institutions, their wellness is of crucial importance for the continued survival of higher education institutions. When managers are not healthy, the perception may be that the organisation they serve may not be healthy either (Grant \& Mack, 2004). To promote wellness and the health of managers, higher education institutions should continuously assess the wellness behaviour and health risk levels of managers.

In the 21st century, leading causes of illness and death are not ascribed to infectious diseases, but to lifestyle diseases. The top ten global risk factors identified by the World Health Organization are low birth and childhood weight, unsafe sex, high blood pressure, tobacco smoke, alcohol abuse, unsafe water, inadequate sanitation and hygiene, high cholesterol levels, indoor smoke from solid fuels, iron deficiency and obesity (Houlton, 2003; Murray \& Lopez, 1997). Research done by the American government on the impact of various factors of current living conditions on mortality rates revealed the following: unhealthy lifestyle $(51 \%)$, polluted environment $(20 \%)$, genetic factors $(9 \%)$ and medical intervention $(10 \%)$ (Serfontein, 2003). Unhealthy lifestyle and negative environmental factors are the most important causes of death. However, managers are able to control these factors. Genetic factors as well as medical intervention play a relatively insignificant role in life expectancy. These and other scientific studies should convince managers that a significant improvement in health is possible if behaviours are changed, thereby avoiding ill health and promoting wellness. Managers cannot control their heredity and age, but they can make sound lifestyle choices. By reducing risk factors, managers are able to improve their state of wellness.

The study on which this article reports comprised an empirical investigation of the six dimensions that influence the level of wellness among managers and an examination of the relationship between wellness behaviour levels and the scales of the probable risk involved in terms of current and future wellness problems experienced by managers. The findings of the study will add value as they can be used to identify specific wellness interventions to remedy poor wellness behaviour and health risk problems. The holistic wellness model that was developed for managers in higher education institutions can be used to assess the wellness behaviour and health risk levels of managers by focusing on physical, emotional, intellectual, social, occupational and spiritual wellness dimensions.

\section{Health and wellness}

To be responsible for one's own wellbeing, one needs to understand the meaning of health, wellness and health risk. Health implies a state of complete physical and mental wellbeing and not merely the absence of disease or infirmity (World Health Organization, 1948). Health is an integrated method of functioning that is oriented toward maximising the potential of the individual. It requires the individual to maintain a continuum of balance and purposeful direction within the environment in which he or she has to function. Wellness can be defined as an approach to personal health that emphasises individual responsibility for wellbeing through the practice of health-promoting lifestyle behaviours (Hurley \& Schlaadt, 1992). Wellness refers to a holistic approach in which mind, body and spirit are integrated. It is a way of life oriented toward optimal health and wellbeing in which body, mind and spirit are meaningfully integrated in a purposeful manner with the goal of living more fully within the human and natural community (Myers, Sweeney \& Witmer, 2000). Wellness is a process that involves striving for balance and integration in one's life, adding and refining skills and rethinking the appropriateness of previous beliefs and stances towards issues (Hatfield \& Hatfield, 1992). The concept of health risk is generally ascribed to Robbins, whose work on the prevention of 
cervical cancer and heart disease during the late 1940s led him to the belief that a medical doctor should record a patient's health hazards to use as a guide when initiating preventive efforts. This in turn led to the creation of a simple health hazard chart that could give the medical examination a more prospective orientation (Beery, Schoenbach \& Wagner, 1986). A health risk appraisal is a systematic approach to collecting information on individuals that identifies risk factors and provides individualised feedback, thereby linking the person to at least one intervention to promote health, sustain functions and/or prevent diseases. A variety of theoretical wellness models were developed that can be used to assess the wellness behaviour levels of employees and that can also serve as a foundation for wellness interventions in organisations.

Hettler (1980) developed a hexagon wellness model comprising six dimensions, namely emotional, intellectual, physical, social, occupational and spiritual wellness. Two paper-and-pencil assessment instruments, the Lifestyle Assessment Questionnaire and the TestWell Wellness Inventory, designed by the National Wellness Institute, are based on the wellness model of Hettler (Hattie, Myers and Sweeney, 2004).

Adams, Bezner, Drabbs, Zambarano and Steinhardt (2000) presented a wellness model to conceptualise and measure the spiritual and psychological dimensions in a college population. Their model is founded on three principles common to all conceptualisations of wellness, namely multidimensionality, balance among dimensions and salutogenesis (defined as promoting health rather than illness). The model and measurements include the physical, social, emotional, intellectual, spiritual and psychological dimensions of health and are dynamically bi-directional. This model serves as the theoretical basis for the Perceived Wellness Survey, which was conducted in a college population and was salutogenically rather than pathogenically focused (Adams et al., 2000). Witmer and Sweeney (1992) incorporated the wellness theory and research concepts from psychology, anthropology, sociology, religion and education into a holistic model of wellness and illness prevention over the lifespan of an individual to be used as a basis for counselling interventions. The results of research and theoretical perspectives from personality, social and clinical health, stress management, behavioural medicine, psychoneuroimmunology, ecology, contextualism and development psychology are foundations for the revised model (Hattie et al., 2004). The revised model proposes five life tasks, depicted in a wheel that are interrelated and interconnected. These five tasks are (1) spirituality, (2) work and leisure, (3) friendship, (4) love, and (5) self-direction (Meyers et al., 2000). According to Hattie et al. (2004), the life task of self-direction can be subdivided into 12 tasks, namely:

1. a sense of worth

2. a sense of control

3. realistic beliefs

4. emotional awareness and coping

5. problem solving and creativity

6. a sense of humour

7. nutrition

8. exercise

9. self-care

10. stress management

11. gender identity

12. cultural identity.

These life tasks interact dynamically with a variety of life forces, including one's family, community, religion, education, government, the media and business/industry. The Wellness Evaluation of Lifestyle aimed to assess each of the individual characteristics in the Wheel of Wellness Model.

To conceptualise, explain and understand the complexity of wellness, a preliminary wellness model for managers, adapted from the models developed by Adams et al. (2000), Edlin, Golanty and McCormack-Brown (1998), Hettler (1980), Witmer

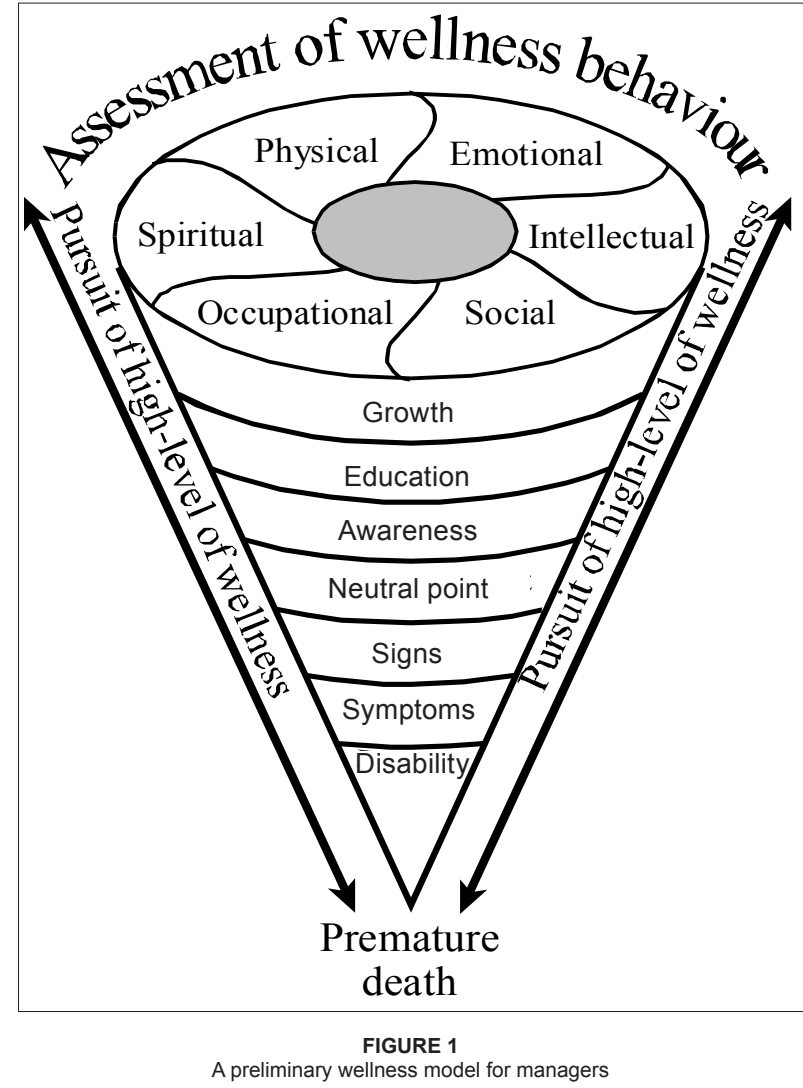

and Sweeney (1992) and Myers et al. (2000) was developed (see Figure 1).

This model forms the theoretical foundation for this article. The preliminary wellness model for managers defines health in terms of the whole person and encompasses the emotional, intellectual, spiritual, occupational, social and physical dimensions of individuals (Davies, Davies \& Heacock, 2003; Edlin et al., 1998; Hettler, 1980; Sapp, 2004). The wellness model places considerable emphasis on health promotion and environmental protection to maintain healthy communities and also stresses the importance of health education and disease prevention for individuals (Dobson \& Lepnurm, 2000). The model focuses on optimal health, the prevention of disease and positive mental and emotional states, and proposes that health is a state of optimum wellness (Edlin et al., 1998).

The wellness continuum allows one to visualise the difference between wellness and medical definitions of health. Individuals move on this continuum toward disability or optimal wellness. The top of the model represents wellness while the bottom represents disability. Disability, in this model, may be a state of poor physical health, poor self-esteem, pessimism, existential frustration, a lack of intellectual stimulation, a negative sense of meaning and purpose in life, unhappiness at work, unhealthy and conflicting relationships, an unsafe and unhealthy work environment, or any combination of these factors (Adams et al., 2000). Any of these conditions could lead to physical illness or disease. There is also a relationship between the various dimensions of wellness. Ideally, these should be in a state of equilibrium. Wellness is a dynamic process that takes into account the decisions taken on a daily basis regarding lifestyle and risk behaviour. These could include the food one chooses to eat, the amount of exercise one gets, whether one chooses to wear a safety belt, smoke cigarettes, drink alcohol or abuse drugs or whether one resides in a polluted environment. To move towards a state of optimal wellness, individuals should make radical changes in their lifestyle choices and reduce risk behaviour. These changes will equip individuals to live full, 
responsible, rewarding lives in an extremely complex world.

The study focuses on the theoretical foundation of the six selected variables or dimensions of wellness, namely physical, social, emotional, intellectual, occupational and spiritual. Physical wellness is divided into three sub-dimensions, namely physical fitness and nutrition, medical self-care, and safety and lifestyle. Social wellness is divided into two sub-dimensions, namely environmental wellness and social awareness, while emotional wellness is divided into emotional awareness and sexuality, and emotional management. These dimensions will be discussed in the following paragraphs.

\section{Physical wellness}

The physical dimension involves cardiovascular flexibility and strength, regular physical activity, knowledge about food and nutrition and medical self-care and discourages the use of drugs and excessive alcohol consumption (Botha, 2007). There is a relationship between a sedentary lifestyle and both morbidity and mortality. Low levels of physical fitness are associated with increasing mortality (Blair et al., 1996). A sedentary lifestyle may lead to chronic diseases such as cancer, cardiovascular disease, stroke, diabetes, high blood pressure, bone loss and osteoporosis. Obesity is related to physical inactivity and being overweight is a risk factor for cardiovascular diseases, diabetes, high blood pressure, higher cholesterol, degenerative arthritis, hypertension, osteoarthritis, sleep apnoea and some types of cancers such as breast, colorectal, endometrial, prostate, kidney and gall bladder (Crespo \& Arbesman, 2003; Fontaine, Heo \& Allison, 2005; Proper, Hildebrandt, Van der Beek, Twisk \& Van Mechelen, 2003; Seefeldt, Malina \& Clark, 2002)

Medical self-care implies maintaining a healthy lifestyle and minimising wellness behaviour risks. Individual medical selfcare focuses on updating one's immunisation record, regular self-examination of testes for men and breasts for women, giving up smoking, considering the use of complementary and alternative medicines for chronic diseases, adequate water intake, practising oral hygiene, protecting one's skin from sun damage, maintaining blood pressure at normal levels and keeping one's blood cholesterol levels within an acceptable range (Botha, 2007).

Safety and lifestyle focus on alcohol abuse and drug-impaired driving. Alcohol involvement in crashes has been clearly demonstrated by a number of studies that show substantial increases in crash risks when the blood alcohol concentration (BAC) exceeds $0.10 \mathrm{~g}$ per $100 \mathrm{ml}$ (\%) (Drummer et al., 2003). For a given cause of injury, the risk of fatality increases with the BAC level (Chen, Baker \& Li, 2005). Harrison and Fillmore (2005) and Ogden and Moskowitz (2004) provide evidence that alcohol adversely affects reaction time, impairs tracking (car control), interferes with learning and adoption to unfamiliar tasks and increases error rates. The combination of alcohol, drugs and prescription medicines such as pain relievers, sleeping pills or anti-anxiety medication affects a driver's ability to operate a motor vehicle (National Highway Traffic Safety Administration, 2004).

\section{Social wellness}

Social wellness is comprised of two sub-dimensions, namely environmental wellness and social awareness. Environmental wellness focuses on pollution, specifically solid waste, air and water pollution and global warming (Botha, 2007). According to Bai, Khazaei, Van Eeden and Laher (2007); Curtis, Rea, SmithWillis, Fenyves and Pan (2006); Evans and Smith (2005); Hattingh (2006); Nel (2005) and Zhang, Song and Cai (2007), the general diseases associated with air pollution include chronic obstructive pulmonary diseases, which include obstructive airway diseases such as emphysema and bronchitis, asthma, acute respiratory infections, cardiovascular diseases and cancers.
Haines, Kovats, Campbell-Lendrum and Corvalan (2006); Kovats, Campbell-Lendrum and Matthies (2005) and McMichael, Woodruff and Hales (2006) identified the following adverse effects of climate change on human health. Extreme temperatures such as heat waves may lead to an increase in mortality rate due to cardiovascular, cerebrovascular and respiratory causes, while extreme colds may lead to increased infectious agents such as influenza, respiratory syncytial virus and seasonal haematological changes. The effects of floods, droughts and storms range from immediate effects of physical injury and morbidity and mortality to effects on mental health. Floods can lead to an increase in diarrhoeal and respiratory diseases. Droughts are associated with an increased risk of disease and malnutrition. Higher temperatures also lead to an increase in aero-allergen production that can lead to an increase in allergic disorders such as hay fever and asthma due to a longer pollen season. Higher temperatures shorten the development time of pathogen in vectors and increase the potential transmission to humans, thus leading to an increase in vector-borne diseases such as malaria tick-borne infections and dengue fevers and yellow fever, as well as salmonella. Water warming and flooding may also lead to an increase in water-borne infections such as cholera. If global warming is not curbed, malaria, dengue fever and encephalitis could become common threats, not only in tropical areas, but everywhere in the world. As temperatures rise, disease-carrying mosquitoes and rodents increase in number, infecting people in their wake.

Social awareness is the appraisal of one's circumstances and functioning in society. The dimensions of social wellness include social integration, social acceptance, social contribution, social actualisation and social coherence (Keys, 1998). People who have close friends, friendly neighbours and supportive colleagues are less likely to experience sadness, loneliness, low self-esteem and problems with eating and sleeping (Helliwell \& Putman, 2004). Agneessens, Waege and Lievens (2006) echo these views by stating that social support correlates to lower stress levels, emotional and psychological wellbeing, physical wellbeing, health and the longevity of individuals. Research done by Cattel (2001) revealed that people with more restricted networks were more likely to express feelings associated with negative health outcomes such as anxiety, depression, suffering from headaches and stomach complaints, as well as a variety of other physical complaints. In addition, socially excluded groups shared certain attributes such as feelings of fatalism and hopelessness.

\section{Emotional wellness}

Emotional wellness is the degree to which one feels positive about oneself and life, the capacity to manage one's feelings and related behaviours, including the ability to realistically assess one's limitations and the ability to cope effectively with stress (Leafgren \& Elsenrath, 1986). Emotional wellness is divided into emotional awareness and sexuality, and emotional management. The World Health Organization (2002, cited by Sandfort \& Ehrhardt, 2004) states that sexual health is a state of physical, emotional, mental and social wellbeing related to sexuality. Research has shown that there is a strong positive relationship between relationship satisfaction and sexual satisfaction while experiences of unresolved conflicts and not feeling loved as well as emotional distance have been shown to be associated with lower sexual satisfaction (Byers, 2005). The lack of an intimate relationship may lead to anger, depression and anxiety that adversely affect physical health as well as emotions and feelings (Edlin et al., 1998). Offman and Matheson (2005) are of the opinion that sexual depression involves feeling distressed or disappointed about the quality of one's sex life, or disheartened about a lack of sexual relations with the intimate partner, while sexual anxiety entails feelings of worry, uneasiness or nervousness related to sexual behaviour and is reflected in feelings of discomfort or tension about one's sexual life.

The emotional management dimension refers specifically to stress management, burnout, anxiety and depression 
(Botha, 2007). Stress can produce a number of psychological consequences such as anxiety, frustration, apathy, lowered selfesteem, tension, irritability, job dissatisfaction, aggression and depression (Gibson et al., 2003). All these detract from feelings of wellbeing, contribute to poor concentration, indecision and decreased attention spans. If these stressors cannot be altered people may resort to psychological substitutes such as negativism, anger, feelings of persecution, criticism, displacement, denial, apathy, fantasy, hopelessness, withdrawal, forgetfulness or procrastination (Bloisi, Cook, \& Hunsaker, 2003).

\section{Intellectual wellness}

Intellectual wellness encourages continued learning, problem solving and creativity and involves improving writing and verbal skills, showing an interest in scientific discoveries, keeping abreast of social and political issues, and reading books, magazines and newspapers (Griffin, 2005). According to Myers et al. (2000), intellectual stimulation, including problem solving and creativity, is necessary for healthy brain functioning, hence quality of life across the life span. Paavola and Hakkarainen (2005) state that knowledge-intensive work requires of individuals to surpass themselves continuously, to develop new competencies, to advance their knowledge and understanding as well as to produce innovations and to create new knowledge. A lack of employee development can contribute to a skill depletion that may lead to employee dissatisfaction, poor motivation, little commitment and a loss of productivity due to a non-optimal utilisation of knowledge, skills and abilities (Bhattacharya \& Wright, 2005). Skills underutilisation results in lowered selfesteem, discouragement, futility and feelings of failure and inferiority, depression, a decrease in organisational commitment, increased stress and lowered self-efficacy (Morrison, Cordery, Girardi \& Payne, 2005).

\section{Occupational wellness}

Occupational wellness is the preparation for work from which an individual will gain personal satisfaction and in which one finds enrichment in one's life (Leafgren \& Elsenrath, 1986). This study focuses on two themes related to occupational wellness, namely job satisfaction and work-life balance. Job satisfaction has been found to have a significant, beneficial relationship with factors such as hardiness, commitment, challenge, change, less stress, less anxiety, fewer physical symptoms, finding meaning in life, longevity and greater productivity (Witmer \& Sweeney, 1992). Work-life balance is the maintenance of a balance between responsibilities at work and at home (De Cieri, Holmes, Abbott \& Pettit, 2005). Conflict between an individual's work responsibilities and family responsibilities can significantly affect all aspects of the individual's life. As the amount of workfamily conflict that an individual is experiencing increases, his or her job satisfaction and life satisfaction drop and these individuals report lower levels of general happiness and subjective wellbeing, increased psychological distress levels, higher levels of depression and alcohol abuse, less commitment and decreased levels of attachment, higher intentions to leave their current place of work, increased reports of actual turnover, lower levels of marital satisfaction, increased instances of divorce, parental problems such as juvenile delinquency and violence and increased stress and tension (Grant-Vallone \& Ensher, 2001; Quick, Henley \& Quick, 2004).

\section{Spiritual wellness}

Although there are different conceptualisations of the spiritual dimension of wellness among theorists, there are some common dimensions such as a sense of meaning and purpose in life; connectedness to self, the environment or a higher power; a belief in a unifying life force; hope; honesty; compassion; forgiveness; rituals and recognition of what is held to be sacred (Adams et al., 2000; Ingersoll \& Bauer, 2004). The behaviours of a spiritually well person manifest as positive energy or optimism, the tendency to pursue the truth (honesty), ethical conduct, belief in God or a higher power, respect, understanding, openness, self-motivation, creativity, giving to others, trust, kindness, team orientation, few organisational barriers, a sense of peace and harmony, an aesthetically pleasing workplace, interconnectedness, encouragement of diversity and acceptance (Ingersoll \& Bauer, 2004; Marques, Dhiman \& King, 2005). Spirituality and religion are overlapping but distinctive concepts. Religion involves beliefs, doctrines and rituals that distinguish one group from another and it recognises the involvement in a faith community and responsibility for one another within that community, while spirituality entails individual and personal beliefs (Koenig, 2004). This view is supported by King and Crowther (2004), who define religion as an organised system of beliefs, practices, rituals and symbols designed to facilitate closeness to the sacred or transcendent (God, a higher power or ultimate truth/reality) and to foster an understanding of one's relation and responsibility towards others living together in a community, while spirituality is the personal quest for understanding questions about life, meaning and relationships with the sacred or transcendent, which may (or may not) lead to the development of religious rituals and the formation of a community. One of the suggestions for the existence of a public interest in spirituality is a symptom of increasing levels of isolation, disconnection and existential frustration in current society (Adams et al., 2000). There is among some people a low-grade chronic anxiety and depression based on a sense of helplessness and hopelessness that the world is somehow out of control (White, 2000). Values are an important dimension of spirituality. Values are defined as principles, standards or qualities considered to be worthwhile (Banhegyi, 2002). When people's personal values are congruent with their organisational values, their personal lives are more fulfilled and they feel more optimistic about their jobs (Digh, 1998). A lack of values is the ultimate disease of our time and leads to value illnesses such as apathy, hopelessness and cynicism. These conditions can progress to become physical, psychological and social illnesses (Witmer \& Sweeney, 1992).

The main objective of this study was to explain the development of a holistic wellness model for managers in higher education institutions, and the way in which the model serves as the theoretical foundation for a wellness behaviour and health risk assessment. The secondary objectives were to measure the wellness behaviour levels of managers by focusing on the various wellness sub-dimensions, to identify health risk factors of managers, to calculate the health risk and wellness behaviour scores and to propose wellness interventions. To accomplish these research objectives, the study investigated the correlation between the health risk scores and the wellness behaviour levels of managers, established whether there is a difference between the mean wellness behaviour levels and mean health risk scores of managers of the selected managerial groups, and investigated whether a wellness prediction model can be used, as a holistic dependent variable, to measure the level of wellness against all possible independent variables, the combined wellness behaviour levels and health risks and which wellness behaviour dimensions and health risk levels of managers need interventions.

\section{Research approach}

\section{RESEARCH DESIGN}

The research reported on here was conducted within the quantitative paradigm by utilising a cross-sectional survey to assess the wellness behaviour and health risk levels of managers at two South African tertiary education institutions. The differences in the wellness behaviour and health risk scores can be interpreted in terms of a continuum ranging from low to high levels of risk. The scores were analysed using descriptive and inferential statistics. A holistic wellness behaviour assessment questionnaire consisting of closed-ended questions was used as the measuring instrument. 


\section{Data collection \\ Participants}

The sample frame was the list of names of managers provided by the respective human resource departments of the two institutions, an academic university and a university of technology. The total population of managers at the academic university was 164 and at the university of technology 160. In view of the relatively small number of managers, a census was done on the entire population. The list of managers provided by the respective human resource departments included their e-mail addresses. The researcher created a separate e-mail address list for each participating university. The self-administered questionnaires were sent via e-mail to all managers on the list. A total of 324 questionnaires were sent out to the two institutions. The number of returned questionnaires from the academic university was $42(26 \%)$ and from the university of technology $57(36 \%)$. This brought the average response rate to $28 \%$ ( $\mathrm{n}=$ $89)$. Of the 89 respondents, $36(40.45 \%)$ were employed by the academic university while $53(59.55 \%)$ were working at the university of technology. In terms of faculty or division, the distribution of respondents was: academic 65, support services 22 and the rectorate 2 . The majority of the respondents were male, representing 61 (68.5\%), while females made up $28(31.5 \%)$ of the 89 respondents. The respondents' ages varied between a minimum age of 35 and a maximum of 64 years. In terms of age groups, 65 were in the age group 35 to 45,36 in the age group 46 to 55 and 32 in the age group 56 to 65 . The race composition was 15 Black, 2 Indian, 2 Coloured and 70 White. The highest qualifications ranged from one matric, seven Bachelors degrees, 41 postgraduate degrees and 40 doctoral degrees. The average years of service for heads of academic departments was 14.72 years, directors 12.14 years and members of the rectorate 9.25 years.

\section{Measuring instrument}

The TestWell Wellness Inventory for Adults (TWI-A) was used in a survey to measure the extent to which wellness behaviours reflect wellness risks and problems. This instrument, which was designed by the National Wellness Institute in the United States of America, is based on the six-dimensional wellness model of Hettler (National Wellness Institute, 2005). The TWI-A reportedly measures the extent to which lifestyle behaviours reflect potential risks and hazards (National Wellness Institute, 1992). The TWI-A is a 100-item inventory divided into 10 subscales of 10 items each (National Wellness Institute, 2005).

The self-administered questionnaire includes biographical information and a health risk assessment and also focuses on the perceived wellness of managers covering physical, emotional, intellectual, social, occupational and spiritual dimensions. The physical, social and emotional dimensions are divided into subcategories. The subscales physical fitness and nutrition, medical self-care and safety and lifestyle fall under the physical dimension. The social dimension is subdivided into the subscales of environmental wellness and social awareness. The subscales emotional awareness and sexuality and emotional management are classified under the emotional dimension, while intellectual, occupational and spiritual wellness are not subdivided. The 10 subscales are:

1. physical fitness and nutrition

2. medical self-care

3. safety and lifestyle

4. environmental wellness

5. social awareness

6. emotional awareness and sexuality

7. emotional management

8. intellectual wellness

9. occupational wellness

10. spirituality and values (Stewart, Rowe \& LaLance, 2000).

Each item in the questionnaire is a statement to which the participant responds using the five-point Likert. The totals for each subscale can range from a minimum of 10 to a maximum of 50. The total scores for the questionnaire can therefore range from 100 to 500. According to Wright (personal communication, September 28, 2006), TestWell for Adults was designed primarily as an educational and awareness tool. The cut-off points are: $0 \%$ to $59 \%$ (a need for improvement), $60 \%$ to $79 \%$ (good) and $80 \%$ to $100 \%$ (excellent) (Wright, personal communication, September $28,2006)$. The wellness group results provide an overview of the strengths and weaknesses, while scores lower than $60 \%$ may need careful attention in the design and implementation of interventions through an organisational wellness programme (National Wellness Institute, 2005).

Nine health risk indicators added to the questionnaire by the researcher are body mass index (BMI); smoking status; number of doctor or health professional visits; total hours of sleep per night; reported health status; elevated blood pressure; family history of medical conditions (such as high blood pressure, diabetes, heart attack or angina, stroke and high blood cholesterol); selfreported (diagnosed with) medical conditions such as high blood pressure, diabetes, heart disease or angina, stroke and high blood cholesterol, and alcoholic drinks consumed per day. These identified health risk factors are based on the Behavioural Risks Surveillance System and the National Health Interview Survey that have been designed to assess health risk behaviours (Thompson, Nelson, Caldwell \& Harris, 1998). Of the nine health risk factors, only six were used to determine the health risk score of the respondents (BMI in view of unreliable self-reported values and high blood pressure and number of alcoholic drinks consumed per day both in view of too many missing values were excluded). To determine the high health risk category among the respondents the following health risk indicators were included: all current and ex-smokers, those who have paid more than five visits to a doctor or health professional per year, those who sleep less than seven hours a night, those who report fair or poor physical health status, those with a family history of high blood pressure, diabetes, heart disease or angina, stroke and high blood cholesterol, and those diagnosed with medical conditions such as high blood pressure, diabetes, heart disease or angina, stroke and high blood cholesterol. The statistician and researcher decided that for each condition indicated by the respondent, a score of one was to be allocated. A maximum score of 14 was attainable.

\section{Statistical analysis}

The returned questionnaires were coded and the raw data processed into the Statistical Package for the Social Sciences (SPSS version 14). A descriptive statistical analysis was done to describe the biographical and health risk data while a Cronbach's alpha coefficient test was done to establish the reliability of the questionnaire. The Pearson product moment correlation coefficient was used to determine whether any correlation existed between the 10 sub-dimensions of wellness levels and the health risk scores. T-tests were carried out to compare the mean wellness behaviour levels and mean health risk scores of the managerial groups. A one-way analysis of variance (ANOVA) was conducted to determine the differences between the mean wellness behaviour levels and the mean health risk scores of the three age groups used in this study.

\section{RESULTS}

The researcher used an instrument that had been developed and validated with samples outside the South African context. A reliability test (Cronbach's alpha coefficient) was carried out to ensure the internal consistency of the questionnaire. Aiken (1982, cited by Finchilescu, 2006) argues that, if this scale is to be used to compare groups of people, then a reliability of 0.65 is sufficient. The Cronbach's alpha of each wellness sub-dimension is shown in Table 1.

The Pearson product moment correlation coefficient was used to determine the relationship between the wellness behaviour levels and the health risk scores of managers. The results 
TABLE 1

Cronbach's alpha for the wellness sub-dimensions

\begin{tabular}{lcr}
\hline WELLNESS SUB-DIMENSION & CRONBACH'S ALPHA & NO. OF ITEMS \\
\hline Physical fitness and nutrition & 0.69 & 10 \\
Medical self-care & 0.67 & 10 \\
Safety & 0.76 & 10 \\
Environmental wellness & 0.71 & 10 \\
Social awareness & 0.77 & 10 \\
Sexuality and emotional & 0.81 & 10 \\
awareness & 0.84 & 10 \\
Emotional management & 0.82 & 10 \\
Intellectual wellness & 0.87 & 10 \\
Occupational wellness & 0.85 & 10 \\
Spirituality and values & 0.93 & 100 \\
Full TestWell score & & \\
\hline
\end{tabular}

suggested that there were no significant correlations between the mean physical fitness and nutrition, medical self-care, safety, environmental wellness, social awareness, intellectual wellness and spirituality and values sub-dimensions and the health risk scores of managers. However, there was a significant negative relationship between sexuality and emotional awareness $(-0.401)$, a small negative relationship between emotional management (-0.297), and a negative relationship between occupational wellness (-0.323) and the health risk score (see Table 2). The negative correlations suggested that, with an increase in sexuality and emotional awareness, emotional management and occupational wellness levels, there would be a decreasing health risk.

T-tests were used to compare the mean wellness behaviour levels and mean health risk scores of the different managerial groups and an ANOVA was conducted to compare the mean scores of the three age groups (see Tables 3 and 4). The mean scores on the wellness behaviour levels and health risk between managers at the academic university and university of technology were very similar, with the exception of emotional management. The average score on emotional management for the university of technology managers was 40.4 out of a possible $50(80.8 \%)$, while the average score for managers at the academic university was 38.28 out of a possible $50(76.56 \%)$. On average, the emotional management score of the university of technology managers was $4.24 \%$ higher than that of their counterparts at

TABLE 2

Correlation between the wellness behaviour levels and health risk scores of managers

\begin{tabular}{lrc}
\hline WELLNESS SUB-DIMENSION & $\begin{array}{r}\text { HEALTH RISK SCORES } \\
\text { PEARSON PRODUCT } \\
\text { MOMENT CORRELATION } \\
\text { COEFFICIENT VALUE } \\
\text { OF }(r)\end{array}$ & P VALUES \\
\hline Physical fitness and nutrition & -0.140 & 0.189 \\
Medical self-care & 0.068 & 0.528 \\
Safety & -0.042 & 0.697 \\
Environmental wellness & -0.026 & 0.808 \\
Social awareness & -0.162 & 0.130 \\
Sexuality and emotional & $-0.401^{* *}$ & 0.000 \\
awareness & $-0.297^{* *}$ & 0.005 \\
Emotional management & -0.073 & 0.497 \\
Intellectual wellness & $-0.323^{* *}$ & 0.002 \\
Occupational wellness & -0.195 & 0.067 \\
Spirituality and values & & \\
\hline
\end{tabular}

the academic university. Since all the $p$ values are greater than 0.05 , the mean scores of the two groups of managers are not statistically significantly different. The $p$ values of mean scores of the wellness behaviour levels and health risk scores between heads of academic departments and directors of support services were also greater than 0.05 , which suggests that there is no statistically significant difference between the mean scores of the two groups.

A comparison of the mean wellness behaviour levels and mean health risk scores between male and female respondents showed that only one wellness behaviour sub-dimension, namely sexuality and emotional awareness, with a p value of 0.048 , was below 0.05 . Since there were no significant differences between the mean scores of nine of the ten wellness behaviour levels and the mean health risk scores, it is concluded that differences between the mean scores of the two groups (male and female) are not statistically significant. A comparison of the mean wellness behaviour levels and health risk scores between postgraduate and $\mathrm{PhD}$ graduate managers indicated no differences between the mean physical fitness and nutrition, medical self-care, safety, environmental wellness, social awareness, sexuality and emotional awareness, occupational wellness, spirituality and values and the health risk scores. However, the exceptions were the emotional management ( $p$ value of 0.032 ) and intellectual wellness ( $p$ value of 0.004 ) sub-dimensions. Since the results showed no significant differences in the means of eight of the ten behaviour levels and the health risk scores, it is suggested that there is no statistically significant difference between the means of the two groups.

The mean wellness behaviour levels and mean health risk scores of managers according to their age groups indicated no differences in the mean physical fitness and nutrition, medical self-care, safety, social awareness, sexuality and emotional awareness, emotional management, intellectual wellness, occupational wellness, spirituality and values and the health risk scores. Although an ANOVA indicated that the mean environmental wellness scores of the three age groups were different, the post hoc tests did not indicate how the age groups differed.

It was not possible to establish whether a wellness prediction model could be used as a holistic dependent variable to measure the level of wellness against independent variables such as physical fitness and nutrition, medical self-care, safety, environmental wellness, social awareness, sexuality and emotional awareness, emotional management, intellectual wellness, occupational wellness, spirituality and values and the health risk scores. The data were of such a nature that a linear regression model could not be used, as the variables were not distributed normally. A logistical regression could only be done if a comparison was made between two groups of managers, namely one group with high wellness behaviour levels and low health risk scores and another group with low wellness behaviour levels and high health risk scores. All the managers fell into one group characterised by high wellness behaviour levels and low health risk scores and as a result a comparison was not an option. Although a wellness prediction model cannot be used as a holistic dependent variable to measure the level of wellness against all possible variables, the model can be used to assess the wellness behaviour and health risks levels of managers.

\section{DISCUSSION}

The primary objective of this research article was to explain the development of a holistic wellness model for managers in higher education institutions and the way in which the model serves as the theoretical foundation for a wellness behaviour and health risk assessment. The results of the data analysis indicated that there was no significant difference between the health risk scores and wellness behaviour levels of the relevant managerial groups. As such, the wellness behaviour levels and 
TABLE 3

T-tests of mean scores of the wellness behaviour levels and health risk scores between the four selected managerial groups

\begin{tabular}{|c|c|c|c|c|c|}
\hline \multirow[b]{3}{*}{ Physical fitness and nutrition } & MEAN & SD & MEAN & SD & \\
\hline & \multicolumn{2}{|c|}{ ACADEMIC UNIVERSITY } & \multicolumn{2}{|c|}{ UNIVERSITY OF TECHNOLOGY } & \\
\hline & 28.06 & 7.034 & 27.85 & 6.998 & 0.892 \\
\hline Medical self-care & 30.89 & 6.907 & 29.98 & 7.752 & 0.573 \\
\hline Safety & 45.78 & 5.504 & 44.11 & 5.780 & 0.178 \\
\hline Environmental wellness & 32.97 & 6.217 & 33.87 & 7.144 & 0.543 \\
\hline Social awareness & 41.31 & 5.047 & 41.53 & 4.734 & 0.833 \\
\hline Sexuality and emotional awareness & 43.44 & 5.289 & 42.74 & 5.460 & 0.544 \\
\hline Emotional management & 38.28 & 5.844 & 40.40 & 6.017 & 0.103 \\
\hline Intellectual wellness & 42.25 & 4.819 & 42.15 & 5.859 & 0.933 \\
\hline Occupational wellness & 38.86 & 6.634 & 39.43 & 6.999 & 0.700 \\
\hline Spirituality and values & 42.06 & 7.059 & 42.04 & 5.244 & 0.989 \\
\hline \multirow[t]{2}{*}{ Health risk scores } & 2.56 & 1.796 & 2.85 & 2.397 & 0.534 \\
\hline & \multicolumn{2}{|c|}{$\begin{array}{l}\text { HEADS OF ACADEMIC } \\
\text { DEPARTMENTS }\end{array}$} & \multicolumn{2}{|c|}{$\begin{array}{l}\text { DIRECTORS OF SUPPORT } \\
\text { SERVICES }\end{array}$} & \\
\hline Physical fitness and nutrition & 27.54 & 6.892 & 29.18 & 7.513 & 0.347 \\
\hline Medical self-care & 29.95 & 6.967 & 31.68 & 8.632 & 0.347 \\
\hline Safety & 44.82 & 5.769 & 44.86 & 5.784 & 0.973 \\
\hline Environmental wellness & 32.74 & 6.389 & 35.64 & 7.719 & 0.085 \\
\hline Social awareness & 41.05 & 4.728 & 42.41 & 5.234 & 0.259 \\
\hline Sexuality and emotional awareness & 42.75 & 5.417 & 43.59 & 5.509 & 0.534 \\
\hline Emotional management & 38.95 & 5.991 & 40.82 & 6.037 & 0.211 \\
\hline Intellectual wellness & 42.32 & 5.403 & 41.64 & 5.835 & 0.615 \\
\hline Occupational wellness & 38.98 & 6.639 & 39.77 & 7.445 & 0.642 \\
\hline Spirituality and values & 42.11 & 6.011 & 41.45 & 6.224 & 0.663 \\
\hline \multirow[t]{2}{*}{ Health risk scores } & 2.88 & 2.240 & 2.23 & 1.998 & 0.231 \\
\hline & \multicolumn{2}{|c|}{ FEMALE } & \multicolumn{2}{|c|}{ MALE } & \\
\hline Physical fitness and nutrition & 28.89 & 7.593 & 27.49 & 6.690 & 0.382 \\
\hline Medical self-care & 30.04 & 7.162 & 30.49 & 7.553 & 0.789 \\
\hline Safety & 45.43 & 6.691 & 44.49 & 5.214 & 0.475 \\
\hline Environmental wellness & 32.36 & 7.689 & 34.03 & 6.290 & 0.280 \\
\hline Social awareness & 40.79 & 5.209 & 41.74 & 4.669 & 0.392 \\
\hline Sexuality and emotional awareness & 44.68 & 5.651 & 42.26 & 5.108 & 0.048 \\
\hline Emotional management & 38.29 & 5.792 & 40.11 & 6.061 & 0.184 \\
\hline Intellectual wellness & 42.68 & 4.603 & 41.97 & 5.796 & 0.569 \\
\hline Occupational wellness & 39.07 & 6.733 & 39.26 & 6.916 & 0.903 \\
\hline Spirituality and values & 42.75 & 5.739 & 41.72 & 6.143 & 0.456 \\
\hline \multirow[t]{2}{*}{ Health risk scores } & 2.50 & 2.152 & 2.84 & 2.185 & 0.500 \\
\hline & \multicolumn{2}{|c|}{ POSTGRADUATE } & \multicolumn{2}{|c|}{ PhD GRADUATE } & \\
\hline Physical fitness and nutrition & 27.17 & 7.307 & 28.65 & 6.875 & 0.351 \\
\hline Medical self-care & 29.12 & 8.880 & 31.30 & 6.153 & 0.203 \\
\hline Safety & 44.73 & 5.119 & 44.75 & 6.547 & 0.989 \\
\hline Environmental wellness & 33.80 & 7.260 & 33.20 & 6.014 & 0.685 \\
\hline Social awareness & 42.17 & 4.324 & 40.70 & 5.244 & 0.172 \\
\hline Sexuality and emotional awareness & 43.05 & 5.468 & 43.23 & 5.250 & 0.883 \\
\hline Emotional management & 40.85 & 6.540 & 37.93 & 5.446 & 0.032 \\
\hline Intellectual wellness & 43.85 & 4.942 & 40.48 & 5.164 & 0.004 \\
\hline Occupational wellness & 39.78 & 6.962 & 38.33 & 6.498 & 0.334 \\
\hline Spirituality and values & 42.90 & 4.989 & 41.05 & 6.835 & 0.167 \\
\hline Health risk scores & 2.80 & 2.261 & 2.55 & 1.921 & 0.586 \\
\hline
\end{tabular}

health risk scores of managers at the two sample universities were combined to determine the overall wellness status. The combined health risk scores came to an average of 2.73 out of a possible $14(19.50 \%)$, while the combined average wellness behaviour level of managers at the two sample universities was $76.80 \%$. The combined wellness behaviour levels are shown in Table 5.

The physical fitness and nutrition wellness dimension (56\% - less than the 60th percentile) was identified as a weakness among managers. This necessitates physical and nutritional interventions. The borderline score for medical self-care (61\%) that includes aspects such as updating one's immunisation record, regular self-examination of testes for men and breasts for women, stopping smoking, using complementary and alternative medicines for chronic diseases, adequate water intake, practising oral hygiene, protecting one's skin from sun damage, maintaining blood pressure at normal levels and maintaining one's blood cholesterol levels within an acceptable range also necessitate a pro-active intervention strategy. The 
TABLE 4

ANOVA to compare the mean scores of the wellness behaviour levels and health risk scores between the three age groups

\begin{tabular}{|c|c|c|c|c|c|c|c|}
\hline \multirow[b]{3}{*}{ WELLNESS SUB-DIMENSION } & \multicolumn{6}{|c|}{ AGE (YEARS) } & \multirow[b]{3}{*}{ P VALUE } \\
\hline & \multicolumn{2}{|c|}{$35-45$} & \multicolumn{2}{|c|}{$46-55$} & \multicolumn{2}{|c|}{$56-65$} & \\
\hline & MEAN & SD & MEAN & SD & MEAN & SD & \\
\hline Physical fitness and nutrition & 27.95 & 9.552 & 27.19 & 6.476 & 28.75 & 5.524 & 0.661 \\
\hline Medical self-care & 31.57 & 8.750 & 29.08 & 6.185 & 30.97 & 7.706 & 0.400 \\
\hline Safety & 43.81 & 6.030 & 44.42 & 6.299 & 45.84 & 4.684 & 0.397 \\
\hline Environmental wellness & 32.10 & 7.341 & 32.17 & 6.092 & 35.94 & 6.604 & 0.038 \\
\hline Social awareness & 42.38 & 5.035 & 41.22 & 5.249 & 41.06 & 4.257 & 0.593 \\
\hline Sexuality and emotional awareness & 45.10 & 5.019 & 42.44 & 5.521 & 42.31 & 5.239 & 0.128 \\
\hline Emotional management & 41.00 & 5.683 & 38.33 & 6.113 & 39.94 & 6.005 & 0.245 \\
\hline Intellectual wellness & 43.71 & 4.233 & 41.31 & 6.122 & 42.19 & 5.239 & 0.274 \\
\hline Occupational wellness & 40.57 & 5.372 & 37.83 & 7.755 & 39.84 & 6.456 & 0.278 \\
\hline Spirituality and values & 42.81 & 3.970 & 41.28 & 6.755 & 42.41 & 6.283 & 0.599 \\
\hline Health risk scores & 2.52 & 2.228 & 2.58 & 2.285 & 3.03 & 2.024 & 0.620 \\
\hline
\end{tabular}

TABLE 5
Combined average wellness behaviour levels of managers at the two sample universities

\begin{tabular}{|c|c|c|c|c|c|}
\hline WELLNESS SUB-DIMENSION & No. & MINIMUM & MAXIMUM & MEAN & STD. DEVIATION \\
\hline Physical fitness and nutrition & 89 & 12 & 46 & 27.93 & 6.974 \\
\hline Medical self-care & 89 & 11 & 49 & 30.35 & 7.395 \\
\hline Safety & 89 & 26 & 50 & 44.79 & 5.698 \\
\hline Environmental wellness & 89 & 20 & 50 & 33.51 & 6.762 \\
\hline Social awareness & 89 & 28 & 50 & 41.44 & 4.836 \\
\hline Sexuality and emotional awareness & 89 & 27 & 50 & 43.02 & 5.372 \\
\hline Emotional management & 89 & 22 & 50 & 39.54 & 6.006 \\
\hline Intellectual wellness & 89 & 26 & 50 & 42.19 & 5.433 \\
\hline Occupational wellness & 89 & 17 & 49 & 39.20 & 6.821 \\
\hline Spirituality and values & 89 & 22 & 50 & 42.04 & 6.006 \\
\hline
\end{tabular}

combined health risk scores of managers were very low with an average of 2.73 out of a possible score of $14(19.50 \%)$, which indicates low health risk levels.

The instrument, the TestWell Wellness Inventory, was used in a number of earlier studies to measure the mean wellness behaviour levels of high school and college students (DiMonda, 2005; Owen, 1999; Stewart et al., 2000). However, the results of the current study cannot be compared with the above-mentioned studies as the contexts as well as the populations differed.

This research contributed to the development of a holistic model for managers at South African tertiary institutions. The wellness behaviour of managers was measured on 10 wellness sub-dimensions. The questionnaire included nine health risks assessment questions to determine the health risk score. Of these nine, only six were used to measure the health risk scores of managers. Therefore, the health risk score is the 11th independent variable influencing wellness as a dependent variable. A diagram of this model appears in Figure 2.

The model is comprised of 11 independent variables, namely physical fitness and nutrition, medical self-care, safety, environmental wellness, social awareness, sexuality and emotional awareness, emotional management, intellectual wellness, occupational wellness, spirituality and values and the health risk score. The 10 sub-dimensions are divided into 10 categories in the questionnaire, while a health risk category is added as the 11th dimension of the model.

The study reported on here contributed to the growing body of literature on wellness and healthy lifestyle behaviour. The holistic wellness behaviour assessment provided managers at the two sample universities with an indication of their wellness behaviour levels and the areas that need improvement. The results of the study showed that the measuring instrument used was valid and reliable for assessing the wellness status of managers. The holistic wellness model proposed in this article could serve as a theoretical framework for future scientific wellness behaviour and health risk assessments that will enable tertiary institutions to devise appropriate interventions.

\section{Limitations}

The respondents had to report on their own wellness behaviour and health risk status. The probability exists that the self-reported values were based on the respondents' own perceptions of their wellness behaviour and health risk status and not on factual information. In view of the unreliability of self-reported values, only six of the nine health risk factors were used to calculate the health risk scores. The sampling bias was strengthened by the fact that there was an over-representation of respondents from the university of technology, white males and heads of academic departments. These findings cannot be generically applied to the higher education institutions included in the sample or to the other 19 South African higher education institutions. In view of the relatively small number of respondents, a factor analysis on the TWI-A instrument could not be done. The low response rate created a response and representative bias problem that made it difficult to apply the results obtained to the entire managerial population of the two sample universities. Although the results may not be deemed as representative of the entire tertiary population, it is a useful first step in creating an awareness of wellness and healthy lifestyle behaviour.

\section{Suggestions for future research}

In future, longitudinal studies should be conducted to measure 


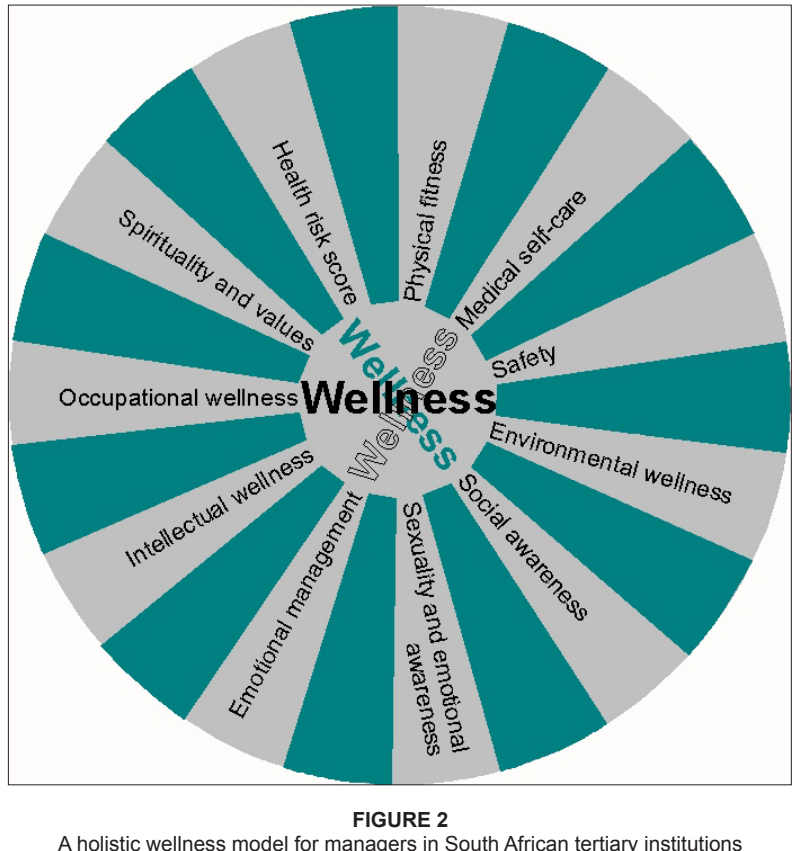

the impact of physical fitness and nutrition and medical selfcare interventions on stress, health care costs, satisfaction and motivation, performance, turnover, absenteeism, morale, productivity, retention, loyalty and quality of life. In order to gain top management's support for investing in wellness and health promotion, research should be done on the return on investment of the proposed interventions. To change the wellness and lifestyle behaviour of managers, further research on behavioural modification theories or models such as the Cognitive Learning Theory, Transtheoretical Model and Health Belief Model should be done. Future research should cover a representative sample of many tertiary institutions in order to enhance external validity of this research. Future research is also necessary to identify other possible independent variables that may influence and determine wellness as a dependent variable. Finally, future researchers, with samples from other universities, should conduct a factorial analysis to enhance the psychometric properties of the TWI-A instrument.

\section{REFERENCES}

Adams, T.B., Bezner, J.R., Drabbs, M.E., Zambarano, R.J., \& Steinhardt,M.A.(2000). Conceptualizationand measurement of the spiritual and psychological dimensions of wellness in a college population. Journal of American College Health, 48, 165-173.

Agneessens, F., Waege, H., \& Lievens, J. (2006). Diversity in social support by roles: A typology. Social Networks, 28, 427-441.

Bai, N., Khazaei, M., Van Eeden, S.F., \& Laher, I. (2007). The pharmacology of particulate matter air pollution-induced cardiovascular dysfunction. Pharmacology \& Therapeutics, $113,16-29$.

Banhegyi, S. (2002). Why value statements don't work. HR Future, 2(6), 42-43.

Beery, W.L., Schoenbach, V.J., \& Wagner, E.H. (1986). Health risk appraisal: Methods and programs. Hyattsville: National Center for Health Services Research and Health Care Technology.

Bhattacharya, M., \& Wright, P.M. (2005). Managing human assets in an uncertain world: Applying real options theory to HRM. International Journal of Human Resource Management, 16, 929-948.

Blair, S.N., Kampert, J.B., Kohl, H.W., Barlow, C.E., Macera, C.A., Paffenbarger. R.S., et al. (1996). Influences of cardiorespiratory fitness and other precursors on cardiovascular disease and all-cause mortality in men and women. Journal of the American Medical Association, 275, 205-210.
Bloisi, W., Cook, C.W., \& Hunsaker, P.L. (2003). Management and organisational behaviour. Berkshire: McGraw-Hill Education.

Botha, P.A. (2007). Development of a holistic wellness model for managers in tertiary institutions. Unpublished doctoral thesis. University of Pretoria, Pretoria, South Africa.

Byers, E.S. (2005). Relationship satisfaction and sexual satisfaction: A longitudinal study of individuals in longterm relationships. The Journal of Sex Research, 42(2), 113118.

Cattel, V. (2001). Poor people, poor places, and poor health: The mediating role of social networks and social capital. Social Sciences and Medicine, 52, 1501-1516.

Chen, L.H., Baker, S.P., \& Li, G. (2005). Drinking history and risk of fatal injury: Comparison among specific injury causes. Accident Analysis and Prevention, 37, 245-251.

Chunda, R.C., \& Cooper, C.L. (2002). Does privatization affect corporate culture and employee well-being? Journal of Managerial Psychology, 17(3), 21-49.

Crespo, C.J., \& Arbesman, J. (2003). Obesity in the United States. Physician and Sportsmedicine, 31(11), 23-28.

Curtis, L., Rea, W., Smith-Willis, P., Fenyves, E., \& Pan, Y. (2006). Adverse health effects of outdoor air pollutants. Environment International, 32, 815-830.

Davies, J., Davies, R., \& Heacock, S. (2003). A wellness program for faculty. Educational Leadership, May, 68-70.

De Cieri, H., Holmes, B., Abbott, J., \& Pettit, T. (2005). Achievements and challenges for work/life balance strategies in Australian organizations. The International Journal of Human Resource Management, 16(1), 90-103.

Digh, P. (1998). The "I" in ethics. Association Management, 50(8), 105-106.

DiMonda, S. (2005). A comparison of undergraduate student behaviors in six dimensions of wellness and their grade points. Unpublished master's thesis, Dowling College, Oakdale, USA.

Dobson, R., \& Lepnurm, R. (2000). Wellness activities address inequities. Social Science and Medicine, 50, 107-121.

Drummer, O.H., Gerostamoulos, J., Batziris, H., Chu, M. Caplehorn, J., Robertson, M.D., et al. (2003). The involvement of drugs in drivers of motor vehicles killed in Australian road traffic crashes. Accident Analysis and Prevention, 943, $1-10$.

Edlin, G., Golanty, E., \& McCormack-Brown, K.M. (1998). Health and wellness. Sudbury, MA: Jones and Bartlett Publishers.

Evans, M.F., \& Smith, V.K. (2005). Do new health conditions support mortality-air pollution effects? Journal of Environmental Economics and Management, 50, 496-518.

Finchilescu, G. (2006). Measurements. In C. Tredoux \& K. Durrheim (Eds.), Numbers, hypotheses and conclusions: A course in statistics for the social sciences, (pp. 201-229). Cape Town: University of Cape Town Press.

Fontaine, K.R., Heo, M., \& Allison, D.B. (2005). Obesity and prostate cancer screenings in the USA. Public Health, 119, 694-695.

Gibson, J.L., Ivancevich, J.M., \& Donnelly, J.H. (2000). Organizations: Behavior, structure, processes. New York: McGraw-Hill.

Grant, J.M., \& Mack, D.A. (2004). Preparing for battle: Healthy leadership during organisational crisis. Organisational Dynamics, 33(4), 409-425.

Grant-Vallone, E.J., \& Ensher, E.A. (2001). An examination of work and personal life conflict, organizational support, and employee health among international expatriates. International Journal of Intercultural Relations, 25, 261-278.

Griffin, T. (2005). Wellness: A journey for life. Benefits and Wellness. Central Michigan University: United States of America.

Haines, A., Kovats, R.S., Campbell-Lendrum, D., \& Corvalan, C. (2006). Climate change and human health: Impacts, vulnerability and public health. Public Health, 120, 585-596.

Harrison, E.L.R., \& Fillmore, M.T. (2005). Are bad drivers more impaired by alcohol? Sober driving precision predicts impairment from alcohol in a simulated driving task. Accident Analysis and Prevention, 37, 882-889. 
Hatfield, T., \& Hatfield, S.R. (1992). As if your life depended on it: Promoting cognitive development to promote wellness. Journal of Counseling and Development, 71, 164-167.

Hattie, J.A., Myers, J.E., \& Sweeney, J. (2004). A factor structure of wellness: Theory, assessment, analysis, and practice. Journal of Counseling and Development, 82, 354-364.

Hattingh, S.P. (2006). Environmental health. In J. Acutt \& S.P. Hattingh (Eds.), Occupational Health: Management and practice for health practitioners, pp. 464-514). Lansdowne: Juta.

Helliwell, J.F., \& Putman, R.D. (2004). The social context of wellbeing. The Royal Society, 359, 1435-1446.

Hettler, B. (1980). Wellness promotion on a university campus. Family and Community Health, 3(1), 77-95.

Houlton, S. (2003). WHO identifies top ten health risks. Pharmaceutical Executive, February 30. Retrieved October 12, 2005, from http://web22.epnet:pnetcom/citation. asp?tb=1\&_ug=dbs+0\%2Cl $\% 2 \mathrm{C} 2 \% 2 \mathrm{C} 6 \% 2 \mathrm{C} 8 \% 2 \mathrm{C} 10 \%$

Hurley J.S., \& Schlaadt, R.G. (1992). The wellness life style. Guildford: The Dushkin Publishing Group.

Ingersoll, R.E., \& Bauer, A.L. (2004). An integral approach to spiritual wellness in school counseling. Professional School Counseling, 7(3), 301-309.

Keys, C.L.M. (1998). Social well-being. Social Psychology Quarterly, 61(2), 121-140.

King, J.E., \& Crowther, M.R. (2004). The measurement of religiosity and spirituality: Examples and issues from psychology. Journal of Organizational Change, 17(1), 83-101.

Koenig, H.G. (2004). Spirituality, wellness, and quality of life. Sexuality, Reproduction and Menopause, 2(2), 76-82

Kovats, R.S., Campbell-Lendrum, D., \& Matthies, F. (2005). Climate change and human health: Estimating avoidable deaths and disease. Risks Analyses, 25(6), 1409-1418

Leafgren, F., \& Elsenrath, D. E. (1986). The role of campus recreation programs in institutions of higher education. In F. Leafgren (Ed.), Developing campus recreation and wellness programs , pp. 1-95. San Francisco: Jossey-Bass.

Marques J., Dhiman, S., \& King, R. (2005). Spirituality in the workplace: Developing an integral model and a comprehensive definition. The Journal of American Academy of Business, 7(1), 81-91.

McMichael, A., Woodruff, R.E., \& Hales, S. (2006). Climate change and human health: Present and future risks. The Lancet, 367, 859-869.

Morrison, D., Cordery, J., Girardi, A., \& Payne, R. (2005). Job design, opportunities for skills utilization, and intrinsic job satisfaction. European Journal of Work and Organizational Psychology, 14(1), 59-79.

Murray, C.J., \& Lopez, A.D. (1997). Global mortality, disability, and the contribution of risk factors: Global burden of disease study. The Lancet, 349, 1436-1442.

Myers, J.E., Sweeney, T., \& Witmer, J.M. (2000). The wheel of wellness counseling for wellness: A holistic model for treatment planning. Journal of Counsel Development, 78, 251266.

National Highway Traffic Safety Administration. (2004). Connecticut driving under influence screening. Traffic Safety Digest, 1, 1-2.

National Wellness Institute. (1992). TestWell, a wellness inventory. Stevens Point: National Wellness Institute.
National Wellness Institute. TestWell: Wellness inventory Standard edition instructions. Retrieved April 19, 2005, from http://www.testwell.org

Nel, A. (2005). Air pollution-related illness: Effects of particles. Science, 308, 804-806.

Offman, A., \& Matheson, K. (2005). Sexual compatibility and sexual functioning in intimate relationships. The Canadian Journal of Human Sexuality, 14(1-2), 31-39.

Ogden, E.J.D., \& Moskowitz, H. (2004). Effects of alcohol and other drugs on driver performance. Traffic Injury Prevention, 5, 185-198.

Owen, T.R. (1999). The reliability and validity of a wellness inventory. American Journal of Health Promotion, 13(3), 180182.

Paavola, S., \& Hakkarainen, K. (2005). The knowledge creation metaphor - An emergent epistemological approach to learning. Science and Education, 14, 535-557.

Proper, K.I., Hildebrandt, V.H., Van der Beek, A.J., Twisk, J.W.R., \& Van Mechelen, W. (2003). Effect of individual counseling on physical activity fitness and health: A randomized controlled trail in a workplace setting. American Journal of Preventive Medicine, 24(3), 218-226.

Quick, J.D., Henley, A.B., \& Quick, J.C. (2004). The balancing act - At work and at home. Organizational Dynamics, 33(4), 426-438.

Sandfort, T.G.M., \& Ehrhardt, A.A. (2004). Sexual health: A useful public paradigm or a moral imperative. Archives of Sexual Behavior, 33(3), 181-187.

Sapp, A. (2004). Promoting wellness in employees. Retrieved May 15, 2004, from http:/www.bsu/web/amsapp/ employeewellness.htm

Seefeldt, V., Malina, R.M., \& Clark, M.A. (2002). Factors affecting levels of physical activity in adults. Sports Medicine, 32(3), 143-168.

Serfontein, W. (2003). Leef lank en gesond: Voorkom en oorkom die grootste gesondheidsgevare. Cape Town: Tafelberg.

Stewart, J.L., Rowe, D.A., \& LaLance, R.E. (2000). Reliability and validity evidence for the Testwell: Wellness inventory - High school edition (TWI [HS]). Measurement in Physical Education and Exercise Science, 4(3), 1157-1173.

Thompson, B.L., Nelson, D.E., Caldwell, B., \& Harris, J.R. (1998). Assessment of health risks behaviors: A tool to inform consumers, providers, health care organizations and purchasers. American Journal of Preventive Medicine, 16(1), $48-59$.

White, J. (2000). Soul at work. Benefits Canada, 24(1), 17.

Witmer, J.M., \& Sweeney, T.J. (1992). A holistic model for wellness and prevention over the life span. Journal of Counseling and Development, $71,140-148$.

World Health Organization. (1948). Preamble of the Constitution of the World Health Organization as adapted by the International Health Conference, New York, June, 1946; signed on 22 July 1946 by the representatives of 61 States (Official records of the World Health Organization, no. 2, p. 100) and entered into force on 7 April 1948.

Zhang, M., Song, Y., \& Cai, X. (2007). A health-based assessment of particulate air pollution in urban areas of Beijing in 20002004. Science of the Total Environment, 376, 100-108. 